\title{
Optimization of intersecting straight lines methods for the evaluation of acidity constants of single equilibria from spectrophotometric data
}

\begin{abstract}
The acid dissociation constant $(\mathrm{Ka})$ is among the most frequently used physicochemical parameters, and its determination is of interest to many research fields. A number of graphical methods has been proposed for the spectrophotometric evaluation of acidity constants of single equilibrium $\mathrm{HR}=\mathrm{H}+\mathrm{R}$ (charges omitted for the sake of generality), in those cases in which the limit absorbance's of the pure species HR or R, A1 and $\mathrm{A} 0$, respectively, are unknowns. The raw values of absorbance's versus $\mathrm{pH}$ data are transformed in linear functions, which allow to evaluate the unknown parameter $\mathrm{Ka}$ and $\mathrm{A} 0 /$ or $\mathrm{A} 1$ by a graphical approach or by the application of the least squares method. Among the various methods proposed the double reciprocal, Agren-Sommer and Nash methods yield to a family of intersecting straight lines when experimental measurements of absorbance and $\mathrm{pH}$ are made at different wavelengths. The purpose of this paper is to critically examine these methods on the basis of the requirements of single linear regression.
\end{abstract}

Keywords: intersecting straight lines methods, acidity constants, spectrophotometric data
Volume 6 Issue 4 - 2018

\author{
Julia Martín,' Agustín G Asuero, ${ }^{2}$ M Angeles \\ Herrador, ${ }^{2}$ Gustavo González ${ }^{3}$ \\ 'Department of Analytical Chemistry, Escuela Politécnica \\ Superior, University of Seville, Spain \\ 2Department of Analytical Chemistry, Faculty of Pharmacy, \\ University of Seville, Spain \\ ${ }^{3}$ Department of Analytical Chemistry, Faculty of Chemistry, \\ University of Seville, Spain
}

Correspondence: Julia Martín, Department of Analytical Chemistry, Escuela Politécnica Superior, University of Seville, C/ Virgen de África, 7, E-4I0II Seville, Spain, Tel +34-9-5455-6250, Email jbueno@us.es

Received: July 12, 2018 | Published: August 30, 20188

\section{Introduction}

Among the physico-chemical properties of molecules, the acidity constants are of vital importance both in the analysis of drugs as well as in the interpretation of their mechanism of action. ${ }^{1-4}$ The solution of many galenical problems requires the knowledge of the acidity constants of compounds ${ }^{4}$ of pharmaceutical interest. Many compounds of biological interest have acidity constants, which lie close to each other. Their absorption, further transport and effect in the living organism are affected by the ratio of concentration of protonated and non-protonated forms in various media. Thus, the knowledge of acidity constants is worthy. The evaluation of acidity constants of organic reagents is also of great value to plan analytical experiments, ${ }^{5}$ e.g., the acidity constants can be employed in the design of titration procedures ${ }^{6}$ and to examine the likelihood of separation of mixtures of compounds by extraction.

Although black-box computer software's are easily available nowadays, the spectrophotometric determination of equilibrium constants $^{7}$ of single equilibria, such as acidity constants $\left(\mathrm{K}_{\mathrm{a}}\right)$ of monoprotic acids by graphical plots seems to be valuable, due to the transparency of the linearized methods applied. Spectrophotometry is the choosen method when $\mathrm{pK}$ values are either enough high or low and/or solubility problems ${ }^{8}$ appear. The correct evaluation of $\mathrm{pK}_{\mathrm{a}}$ of substances of therapeutic interest has vital importance in drug analysis and for the interpretation of their mechanisms of action. A number of graphical methods has been proposed ${ }^{9}$ for the spectrophotometric evaluation of acidity constants, $\mathrm{HR}=\mathrm{H}+\mathrm{R}$ (charges omitted for the sake of generality) in those cases in which the limit absorbance of the pure species $\mathrm{HR}, \mathrm{A}_{1}$, or $\mathrm{R}, \mathrm{A}_{0}$, are unknown. Among them, the double reciprocal or Maroni-Calmon, ${ }^{10}$ Agren-Sommer ${ }^{11-12}$ and Nash $^{13}$ methods, lead to a family of intersecting straight lines when experimental measurements of absorbance and $\mathrm{pH}$ are made at varying wavelengths.

In these classical spectrophotometric methods the experimental absorbance $\mathrm{pH}$ curves are linearized. For the straight lines $\left(\mathrm{Y}=\mathrm{a}_{0}+\mathrm{a}_{1}\right.$ $\mathrm{X}$ ) obtained in each case by the least squares method, we may easily evaluate the unknown parameters, that is, the acidity constant $\mathrm{K}_{\mathrm{a}}$, and the unknown absorbance, $\mathrm{A}_{0}$ or $\mathrm{A}_{1}$, from the slope, $\mathrm{a}_{1}$, and the intercept, $\mathrm{a}_{0}$, of the corresponding lines. The expressions applied in the available methods as well as the calculations of $\mathrm{K}_{\mathrm{a}}$ values are shown in Table 1. If the A-pH measurements are made at different wavelengths a set of intersecting straight lines is obtained, given the coordinates of the cut-off points included (summarized) in Table 2. The purpose of this paper is to shown which of the three methods is more appropriate for linear regression analysis.

Table I Expressions used according to various methods and other parameters of interest

\begin{tabular}{llllll} 
Method & Known absorbance limit & Expression & $\mathbf{X}$ & $\mathbf{Y}$ & $\mathbf{K}_{\mathbf{a}}$ \\
\hline & $\mathrm{A}_{0}$ & $Y=\frac{1}{A_{1}}+\frac{K_{a}}{A_{1}} X$ & $\frac{A-A_{0}}{A\left[H^{+}\right]}$ & $\frac{1}{A}$ & $\frac{b}{a}$ \\
Agren-Sommer & $\mathrm{A}_{1}$ & $Y=\frac{1}{A_{0}}+\frac{1}{A_{0} K_{a}} X$ & $\frac{A-A_{1}}{A}\left[H^{+}\right] \frac{1}{A}$ & $\frac{a}{b}$
\end{tabular}


Table Continued..

$\mathrm{A}_{0}$

Maroni-Calmon
$Y=\frac{1}{A_{1}-A_{0}}+\frac{K_{a}}{A_{1}-A_{0}} X$

$A_{1}$

Nash
$A_{0}$

$$
Y=\frac{1}{A_{0}-A_{1}}+\frac{1}{\left(A_{0}-A_{1}\right) K_{a}} X
$$

$Y=\left|\frac{A_{0}-A_{1}}{A_{0}}\right| \frac{1}{K_{a}} X-\frac{1}{K_{a}}$

$A_{1}$
$\frac{1}{\left[H^{+}\right]} \quad \frac{1}{A-A_{0}} \quad \frac{b}{a}$

$\frac{1}{A-A_{1}} \quad \frac{a}{b}$

$\frac{1}{1-A / A_{0}}$

$\frac{1}{\left[H^{+}\right]}-\frac{1}{a}$

$Y=\left|\frac{A_{1}-A_{0}}{A_{1}}\right| K_{a} X-K_{a} \quad \frac{1}{1-A / A_{1}} \quad\left[H^{+}\right] \quad-a$

Table 2 Coordinates of intersecting points in when measurements are made at varying wavelengths

\begin{tabular}{lll}
\hline Method & Limit absorbance & Intersecting point \\
\hline Agren-Sommer and & $\mathrm{A}_{0}$ known & $\left(-1 / \mathrm{K}_{\mathrm{a}}, 0\right)$ \\
Maroni-Calmon & $\mathrm{A}_{1}$ known & $\left(-\mathrm{K}_{\mathrm{a}}, 0\right)$ \\
& $\mathrm{A}_{0}$ known & $\left(0,-1 / \mathrm{K}_{\mathrm{a}}\right)$ \\
Nash & $\mathrm{A}_{1}$ known & $\left(0,-\mathrm{K}_{\mathrm{a}}\right)$ \\
\hline
\end{tabular}

\section{Theory}

The correct use of the least squares method requires ${ }^{14-15}$ several assumptions when it is applied to linear regression analyses:

a) The measurement of the variable $X$ is assumed error-free.

b) The Y values obtained (replicates) for the same $\mathrm{X}$ value must show a Gaussian distribution.

c) The standard deviation of the $\mathrm{Y}$ values should not change in the range of values covered by the $\mathrm{X}$ values (homocedasticity).

If the various expressions proposed in Table 1 are examined in this regard, it can be accepted in the first instance that conditions b) and c) are met, but not a). Given the different nature of the mathematical function that relates the variables of regression $\mathrm{X}$ and $\mathrm{Y}$ with the experimental values of $\mathrm{A}$ and $\mathrm{pH}$ in each method, condition a) should be checked through the propagation of errors made in the mean values of $\mathrm{A}$ and $\mathrm{pH}$ over the various pairs of data $\mathrm{X}, \mathrm{Y}$ object of the regression.

\section{Error analysis}

Let $\mathrm{z}$ be a function of the variables $\mathrm{A}$ and $\mathrm{pH}, \mathrm{z}=\mathrm{f}(\mathrm{A}, \mathrm{pH})$. The errors involved in the measurement of $\mathrm{A}$ and $\mathrm{pH}$ will be propagated through $\mathrm{Z}$ according ${ }^{16}$ to the random error propagation law

$$
s_{z}=\left(\frac{\partial z}{\partial A}\right)^{2} s_{A}^{2}+\left(\frac{\partial z}{\partial p H}\right)^{2} s_{p H}^{2}
$$

where $\mathrm{s}_{\mathrm{A}}^{2}$ and $\mathrm{s}_{\mathrm{pH}}{ }^{2}$ are the variances (squared standard deviations) of the absorbance and $\mathrm{pH}$, respectively. Measurements of $\mathrm{A}$ and $\mathrm{pH}$ are independent, and then $\operatorname{cov}(\mathrm{A}, \mathrm{pH})=0$. The application of the Eqn. (1) to the expression of the three methods tested is compiled in Table 3.

If it is assumed that $\mathrm{s}_{\mathrm{A}}$ and $\mathrm{s}_{\mathrm{pH}}$ have the values of 0.001 and 0.01 , respectively, given the precision of common spectrophotometers and $\mathrm{pH}$-meters, we may evaluate the standard deviation of the variables $\mathrm{X}$ and $\mathrm{Y}, \mathrm{s}_{\mathrm{X}}$ and $\mathrm{s}_{\mathrm{Y}}$, respectively, by using five series of synthetic absorbance versus $\mathrm{pH}$ data, with 21 points uniformly distributed in the $\mathrm{pH}$ range $\mathrm{pK}_{\mathrm{a}} \pm 1$, applying the Monte Carlo method, detailed e.g. in reference. ${ }^{17}$ The results obtained from this study, expressed as relative standard deviations $\mathrm{s}_{\mathrm{X}} / \mathrm{X}$ and $\mathrm{s}_{\mathrm{Y}} / \mathrm{Y}$ are shown in Table 4.

Table 3 Propagation of errors in the different variables

\begin{tabular}{ll}
\hline Method & Variance of variables \\
\hline & $S_{Y}^{2}=S_{A}^{2} / A^{4}$ \\
$\mathrm{~A}_{0}$ & $S_{X}^{2}=A_{0}^{2} S_{A}^{2} /\left(A^{4}\left[H^{+}\right]^{4}\right)+\left(A-A_{0}\right)^{2} \ln ^{2} 10 S_{p H}^{2} /\left(A^{2}\left[H^{+}\right]^{2}\right)$
\end{tabular}

Agren-Sommer

$A_{1}$

$$
\begin{aligned}
& S_{Y}^{2}=S_{A}^{2} / A^{4} \\
& S_{X}^{2}=\left[H^{+}\right]^{2} A_{1}^{2} S_{A}^{2} / A^{4}+\left(\left(A-A_{1}\right)^{2} / A^{2}\right) \ln ^{2} 10\left[H^{+}\right]^{2} S_{p H}^{2}
\end{aligned}
$$


Table Continued...

$A_{0}$

Maroni-Calmon

$A_{1}$

$\mathrm{A}_{0}$

Nash

$A_{1}$

$$
\begin{aligned}
& S_{Y}^{2}=S_{A}^{2} /\left(A-A_{0}\right)^{4} \\
& S_{X}^{2}=\ln ^{2} 10 S_{p H}^{2} /\left[H^{+}\right]^{2}
\end{aligned}
$$

$$
\begin{aligned}
& S_{Y}^{2}=S_{A}^{2} /\left(A-A_{1}\right)^{2} \\
& S_{X}^{2}=\left[H^{+}\right]^{2} \ln ^{2} 10 S_{p H}^{2} \\
& S_{Y}^{2}=\ln ^{2} 10 S_{p H}^{2} /\left[H^{+}\right]^{2} \\
& S_{X}^{2}=A_{0}^{2} S_{A}^{2} /\left(A_{0}-A\right)^{4}
\end{aligned}
$$

$$
\begin{aligned}
& S_{Y}^{2}=\left[H^{+}\right]^{2} \ln ^{2} 10 S_{p H}^{2} \\
& S_{X}^{2}=A_{1}^{2} S_{A}^{2} /\left(A_{1}-A\right)^{4}
\end{aligned}
$$

Table 4 Relative precision of the different regression variables

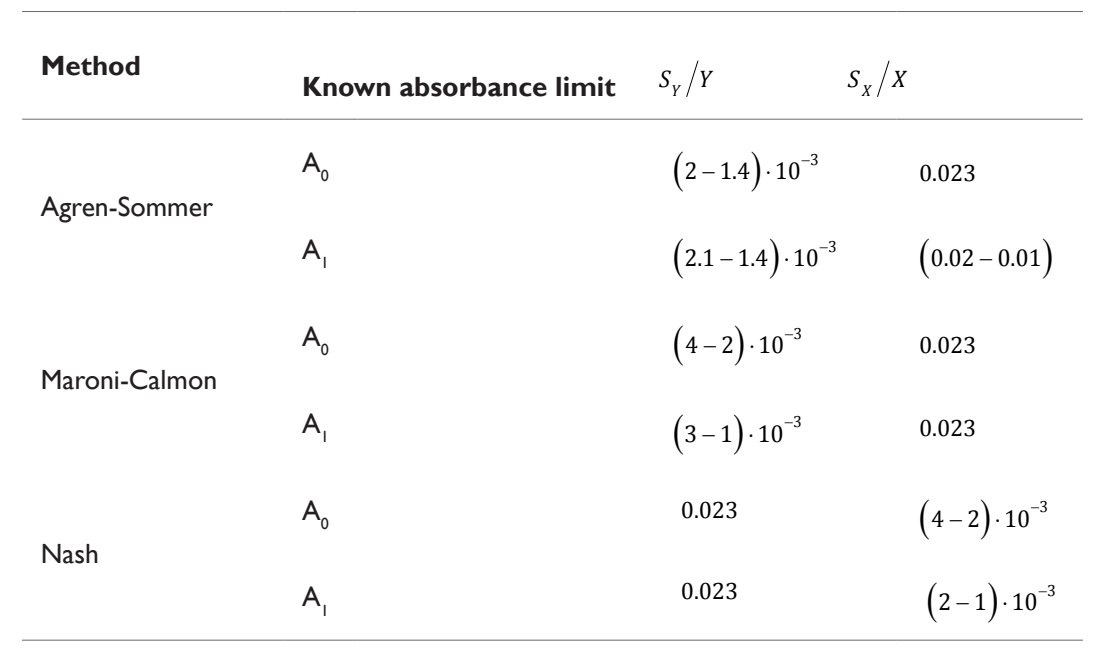

\section{Transformation of Expressions}

It can be seen from results included in Table 4 that the method of Nash led to a greater precision in the measurement of the variable $\mathrm{X}$ compare to the other two methods. If we are interesting in applying both Agren-Sommer and Maroni-Calmon method in a more rigorous way, the role of the variables $\mathrm{X}$ and $\mathrm{Y}$ must be interchanged leading to the expressions found in Table 5. An additional advantage of the transformed expressions is that allow a simple calculation of the standard deviation of $\mathrm{K}_{\mathrm{a}}$ values

$$
s_{K_{a}}=\left|\frac{\partial K_{a}}{\partial a_{0}}\right| s_{a_{0}}
$$

because the acidity constant coincides with the intercept $\left(\mathrm{A}_{0}\right.$ known) or the reciprocal intercept ( $A_{1}$ known) of the corresponding straight line obtained.

By using the classical expressions we obtain instead more complex relationships for the standard deviation of $\mathrm{K}_{\mathrm{a}}$

$$
s_{K_{a}}^{2}=\left(\frac{\partial K_{a}}{\partial a_{0}}\right)^{2} s_{a_{0}}^{2}+\left(\frac{\partial K_{a}}{\partial a_{1}}\right)^{2} s_{a_{1}}^{2}+2\left(\frac{\partial K_{a}}{\partial a_{0}}\right)\left(\frac{\partial K_{a}}{\partial a_{1}}\right) \operatorname{cov}\left(a_{0}, a_{1}\right)
$$

However, by using the new expressions proposed with the synthetic data generated, smaller standard deviations values are obtained (approximately half) than by applying the classical equations. To illustrate the above, a practical application has been developed. 
Table 5 Transformed expressions for the Agren-Sommer and Maroni-Calmon methods

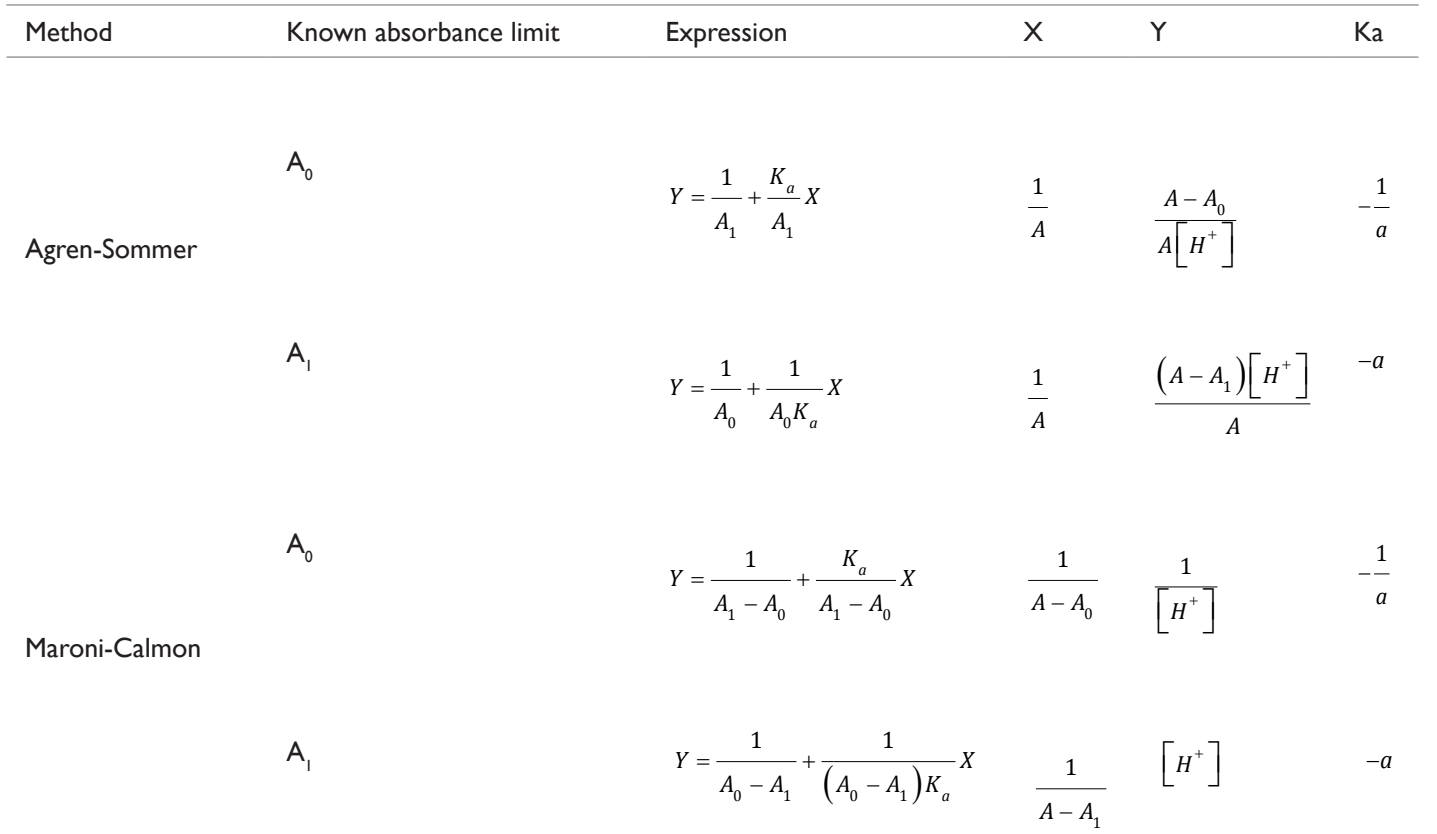

\section{Materials and methods}

In this paper a $\mathrm{pH}$ meter CRISON model $501 \mathrm{pH}$ meter with combined glass- $\mathrm{Ag} / \mathrm{AgCl}$ electrodes (In gold) with a range of use of 0 to $14 \mathrm{pH}$ units, has been used in $\mathrm{pH}$ measurements. A Spectrophotometer SPECTRONIC 2000 (Bausch \& Lomb) provided with a graphic XY recorder and equipped with quartz cells of $1-\mathrm{cm}$ path-length has been used for absorbance measurements.

The two classical methods as well as the new expressions have been applied to the $\mathrm{pK}$ evaluation of the methylglyoxal bis (4-phenyl3thiosemicarbazone) (MGBPT). ${ }^{18-19}$ Although this reagent has two close $\mathrm{pK}$ corresponding to the equilibria of the type expressed in the following scheme ${ }^{20}$

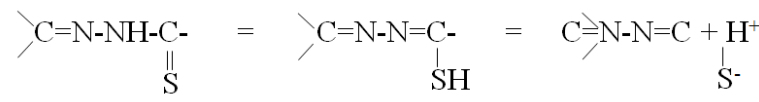

applying the Coleman or Polster methods ${ }^{1,21-23}$ it can be shown that in the range of about $10-12 \mathrm{pH}$, the two species corresponding to the first ionization equilibrium are found from a practical point of view.

To obtain the A-pH curves of the reagent, solutions of MGBPT concentration equal to $1.08 \times 10^{-5} \mathrm{M}$ are prepared in $25-\mathrm{mL}$ volumetric flasks. The appropriate $\mathrm{pH}$ is achieved by adding different volumes of $\mathrm{KOH}$ or $\mathrm{HCl}$ of various concentrations. To ensure the homogeneity of the solutions, N-N'-dimethylformamide (DMF) is added (the optimum solvent for this reagent is a mixture of DMF and water) so that the samples have $60 \% \mathrm{~V} / \mathrm{V}$ of DMF. To fix the ionic strength of the medium in $0.1,2.5 \mathrm{~mL}$ of solution of $\mathrm{KCl} 1 \mathrm{M}$ were added. Finally, it is poured with distilled water in $25 \mathrm{~mL}$ volumetric flasks, and the $\mathrm{pH}$ values measured by passing the solutions to $25 \mathrm{~mL}$ beakers. Absorption spectra are recorded against blanks prepared in the same manner, without reagent. The temperature was about $20 \pm 1^{\circ} \mathrm{C}$.

\section{Results and discussion}

Though somewhat unpopular in the computer era, graphical analysis is a very appropriate method to study the acid-base behaviour of single equilibria from a spectrophotometric point of view. Since we may assume that in the $\mathrm{pH}$ range of choice there are only two species in solution, it is justifiable ${ }^{2}$ to apply the methods already seen. The results obtained are shown in Table 6. Applying to these results the appropriate statistical criteria ${ }^{24}$ we can admit that the average values of $\mathrm{pK}_{\mathrm{a}}$ obtained from the classical expressions did not differ from those obtained with the new expressions. Moreover, there are also no significant differences as regards their precisions.

However, some limitations are inherent to this study:

a) The calculations were only made for values of $\mathrm{s}_{\mathrm{A}}=0.001$ and $\mathrm{S}_{\mathrm{pH}}=0.01$.

b) It was assumed that absolute values of $A$ are independent of the actual values for the whole range of absorbance found.

c) If the Gauss law holds for $\mathrm{A}$ and $\mathrm{pH}$ measurements, this is not necessary so for $\mathrm{X}$ and $\mathrm{Y}$ of the type used for the calculations in the manuscript; a serious objection, however, the authors does not know whether this is.

d) The variance analysis did not include the uncertainty of the instruments readings.

Transmittance and concentration are related by means of a logarithmic relationship, in such a way that small errors in transmittance measurement causing large relative absorbance errors. However, the main source of indeterminate error in modern spectrophotometers lies in the measure of the absorbance. However, the procedure devised in this paper has the inherent advantage of its simplicity, which makes it attractive. Bisthiosemicarbazones are clinically relevant for a variety of diseases, e.g. tuberculosis, viral infections, malaria and cancer. ${ }^{25}$ Copper (II) uncharged lipophilic complexes of bisthiosemicarbazones posses fascinating biological activity ${ }^{26-28}$ including applications in nuclear medicine. ${ }^{28}$ Recent reviews show the biological importance of thiosemicarbazones as anticancer agents..$^{25,29-33}$ 
Table $6 \mathrm{pK}_{\mathrm{al}}$ values at different wavelengths

\begin{tabular}{|c|c|c|c|c|c|c|c|}
\hline \multirow[b]{2}{*}{$\lambda(n m)$} & \multicolumn{2}{|c|}{ Agren-Sommer Method } & \multirow{2}{*}{$\Delta^{* *}$} & \multicolumn{2}{|c|}{ Maroni-Calmon Method } & \multirow{2}{*}{$\Delta^{* *}$} & \multirow[b]{2}{*}{ Nash Method } \\
\hline & Classic & Transformed & & Classic & Transformed & & \\
\hline & 10.903 & 10.926 & 0.023 & 10.961 & 10.965 & 0.004 & 10.951 \\
\hline 340 & & & & & & & \\
\hline 345 & 10.909 & 10.931 & 0.022 & 10.963 & 10.967 & 0.004 & 10.939 \\
\hline$*$ & $10.906 \pm 0.004$ & $10.928 \pm 0.003$ & & $10.962 \pm 0.001$ & $10.966 \pm 0.00 \mid$ & & $10.945 \pm 0.008$ \\
\hline
\end{tabular}

(*) average value \pm standard deviation

$(* *)$ $\mid p K_{a}$ classic $-p K_{a}$ transformed $\mid$

\section{Conclusion}

Among the physico-chemical properties of molecules, the acidity constants are of vital importance both in the analysis of drugs as well as in the interpretation of their mechanism of action. The solution of many galenical problems requires the knowledge of the acidity constants of compounds having pharmaceutical interest. As it has previously indicated, calculation of acidity constants of monoprotic acids by graphical methods may be advantageously used in spite of the existence of modern black-box computer software's. The exchange of the role of the variables $\mathrm{X}$ and $\mathrm{Y}$ of the classical Agren-Sommer and Maroni-Calmon methods resulted in new expressions that fulfil the mathematical conditions required for the regression analysis, and led to more simplified equations for the calculation of the $\mathrm{pK}_{\mathrm{a}}$ and its individual standard deviation. As far as the results are concerned, there are no significant differences and, therefore, this reformulation may be considered valid. Note that bisthiosemicarbazones are biological relevant as shown at the end of the previous section.

\section{Acknowledgements}

None.

\section{Conflict of interest}

Authors declare that there is no conflict of interest.

\section{References}

1. Martin J, Soria AH, Asuero AG. A slope-intercept method for the spectrophotometric evaluation of overlapping acidity constants of diprotic acids when limiting absorbances are known. J Lab Chem Educ. 2018;6(4):107-117.

2. Martin J, Suarez IA, Asuero AG. An annotation of normalized diagrams for the existence of two species of a diprotic acid in solution. Open Access J Chem. 2018;2(1):23-25.

3. Avdeef A, Testa B. Physicochemical profiling in drug research; a brief survey of the state-of-the-art of experimental techniques. Cell Mol Life Sci. 2002;59(10):1681-1689.

4. Asuero AG. A bilogarithmic method for the evaluation of acidity constants of amphoteric substances from solubility measurements. Int $J$ Pharm. 1989;52(2):129-137.

5. Papanastasiou G, Kokkinidis G. Development of iterative methods for the exact determination of acid dissociation constants and specific reaction rates in various ionic or electrochemical systems: A review. Collect Czechoslovak Chem Commun. 2003;68(8):1345-1378.
6. Asuero AG, Michalowski T. Comprehensive formulation of titration curves for complex acid-base systems and its analytical implications Crit Rev Anal Chem. 2011;41(2):151-187.

7. Fuchs H, Gessner R. The result of equilibrium-constant calculations strongly depends on the evaluation method used and on the type of experimental errors. Biochem J. 2001;359(Pt 2):411-418.

8. Avdeef A. Solubility of sparingly-soluble ionizable drugs. Adv Drug Deliv Rev. 2007;59(7):568-590.

9. Meloun M, Havel J, Högfeldt E. Computation of Solution Equilibria, a guide to methods in potentiometry, extraction, and spectrophotometry. Chichester: Ellis Horwood; 1988.

10. Maroni C, Calmon JP. Détermination spectrophotométrique des $\mathrm{pK}$ de dissociation des $\beta$-dicétones. 1. Technique expérimentale et mise au point de méthodes graphiques. Bull Soc Chim France. 1964;1:519-524.

11. Agren A. The complex formation between iron(III) ion and some phenols. II. Salicylic acid and p-amino salicylic acid. Acta Chem Scand. 1954;8(6):1059-1072.

12. Sommer L, Langova M. Spectrophotometric methods for the investigation of metal complex formation. Crit Rev Anal Chem. 1988;19(3):225-269.

13. Nash CP. The calculation of equilibrium constant from spectrophotometric data. J Phys Chem. 1960;64(7):950-953.

14. Asuero AG, Gonzalez AG. Some observations on fitting a straight line to data. Microchem J. 1989;40(2):216-225.

15. Sayago A, Boccio M, Asuero AG. Fitting straight lines with replicated observations by linear regression: the least squares postulates. Crit Rev Anal Chem. 2004;34(1):39-50.

16. Asuero AG, Gonzalez G, de Pablos F, et al. Determination of the optimum working range in spectrophotometric procedures. Talanta. 1988;35(7):531-537.

17. Martin J, Mairena JP, Asuero AG. On the evaluation of autoprotolysis constants of amphiprotic and inert solvents obtained from electrochemical measurements: consideration of liquid junction potentials when necessary. Curr Top Anal Chem. 2016;10:49-71.

18. Herrador MA, Jimenez AM, Asuero AG. Spectrophotometric determination of zinc in potable waters and insulin with methylglyoxal bis(4-phenyl-3-thiosemicarbazone). Analyst. 1987;112(9):1237-1246.

19. Herrador MA. Analytical Applications of Metylglyoxal Bis(4-Phenyl3-Thiosemicarbazone). Seville: PhD Thesis, University of Seville, Department of Analytical Chemistry; 1986.

20. Asuero AG, González-Balairon M. Analytical applications of biacety bis(4-phenyl-3-thiosemicarbazone) and bipyridylglyoxal bis(4-phenyl3-thiosemicarbazone). Microchem J. 1980;25(1):14-45. 
21. Coleman JS, Varga LP, Mastin H. Graphical methods for determining the number of species in solution. Inorg Chem. 1970;9(5):1015-1020.

22. Polster J, Lachmann H. Spectrometric Titrations: Analysis of Chemical Equilibria. Weinheim: VCH; 1989. 433 p.

23. Boccio M, Sayago A, Asuero AG. A bilogarithmic method for the spectrophotometric evaluation of stability constants of $1: 1$ weak compleses from mole ratio data. Int J Pharm. 2006;318(1-2):70-77.

24. Miller JN, Miller JC. Statistics and Chemometrics for Analytical Chemistry. $6^{\text {th }}$ ed. Essex: Pearson; 2010.

25. Heffeter P, Pape VFS, Enyedy EA, et al. Anticancer thiosemicarbazones: chemical properties, interaction with iron metabolism, and resistance development. Antioxid Redox Signal; 2018.

26. Mckenzie-Nickson S, Bush AI, Bamham KJ. Bis(thiosemicarbazone) metal complexes as therapeutics for neurodegenerative diseases. Curr Top Med Chem. 2016;16(27):3058-3068.

27. Djoko KY, Goytia MM, Donnelly PS, et al. Copper(II)bis(thiosemicarbazonato) complexes as antibacterial agents: insights into their mode of action and potential as therapeutics. Antimicrob Agents Chemother. 2015;59(10):6444-6453.
28. Paterson BM, Donnelly PS. Copper complexes of bis (thiosemicarbazones): from chemotherapeutics to diagnostic and therapeutic radiopharmaceuticals. Chem Soc Rev. 2011;40(5):30053018.

29. Suvarapu LN, Somala AR, Kodoru JR, et al.Acritical review on analytical and biological applications of thio- and phenylthiosemicarbaonones. Asian J Chem. 2012;24(5):1889-1898.

30. Kaur H, Gupta M. Recent advances in thiosemicarbazones as anticancer agents. Int J Pharm Chem Biol Sci. 2018;8(2):259-265.

31. Khan T, Ahmad R, Joshi S, et al. Anticancer potential of metal thiosemicarbaone complexes: a review. Der Chem Sinica 2015;6(12):111.

32. Pape VFS, Tóth S, Fürdi A, et al. Design, synthesis and biological evaluation of thiosemicarbazones, hydrazinobenzothiazoles and arylhydrazones as anticancer agents with a potential to overcome multidrug resistance. Eur J Med Chem. 2016;117:335-354.

33. Sharma N, Pathak DP. Combatting challenging aspects of cancer with thiosemicarbazones. Int J Pharm Pharm Sci. 2016;8(8):27-34. 